\title{
Technical and Socio Economic Assessment of Water Mill Sites for Micro Hydro Power Generation in North Shoa Zone of Amhara Region
}

\author{
Gashaw Getenet ${ }^{1,}$, , Yirgalem Damtew ${ }^{2}$ \\ ${ }^{1}$ Department of Mechanical Engineering, Debre Berhan University, Debre Berhan, Ethiopia \\ ${ }^{2}$ Department of Civil Engineering, Debre Berhan University, Debre Berhan, Ethiopia \\ Email address: \\ gashaddis@gmail.com (G. Getenet) \\ ${ }^{*}$ Corresponding author \\ To cite this article: \\ Gashaw Getenet, Yirgalem Damtew. Technical and Socio Economic Assessment of Water Mill Sites for Micro Hydro Power Generation in \\ North Shoa Zone of Amhara Region. American Journal of Energy Engineering. Vol. 7, No. 2, 2019, pp. 45-48. \\ doi: 10.11648/j.ajee.20190702.11
}

Received: May 6, 2019; Accepted: June 13, 2019; Published: July 2, 2019

\begin{abstract}
Use of micro hydropower plants is an ideal method of providing power for off-grid rural communities especially in developing countries like Ethiopia. In Ethiopia only $8 \%$ of the rural community has access to electricity, and the power supply in the country is very low as compared to its population growth. The present study assesses the technical and socio economic aspect of water mill sites in North Shoa zone of Amhara regional state, Ethiopia for the development of micro hydro power plant. Through technical assessment of the flow rate measurement, head measurement and estimation of power generation potential of the mill sites has been done. The socio economic assessment was done by interviewing households, officials and mill owners. The results of the assessment shows that, out of the 14 mill sites investigated, 12 of them has the potential to generate power ranging from $5.52 \mathrm{kw}$ to $38.59 \mathrm{kw}$ with $80 \%$ efficiency during the dry season. It has been observed, the existing as well as former mill sites in North Shoa zone, are mostly located in the mountainous regions which offers an interesting opportunity for micro hydropower generation that would meet the energy demand of the villages at least $5 \mathrm{~km}$ far from the main grid.
\end{abstract}

Keywords: Micro Hydro, Power Plant, Flow Rate, Head, Socio Economic

\section{Introduction}

Energy plays one of the most important role in the development of a country. The source of energy can be fossil fuel, nuclear power, solar, wind, hydro, geothermal, biomass and bio-fuel etc. These sources can be renewable or nonrenewable and renewable energy sources can help countries meet development goals by fulfilling their energy demands.

Ethiopia has abundant renewable energy sources and has the potential to generate over $45,000 \mathrm{MW}$ of electric power from hydropower only [1]. As a result of the country's rapid GDP growth over the previous decade, demand for electricity has been steadily increasing. Almost $85 \%$ of the population of Ethiopia lives in rural area, where only $8 \%$ have access to electricity, and the power supply in the country is very low as compared to its population growth [2]. As a result rural area populations predominantly rely on kerosene and traditional fuel wood to meet their energy demand for various purposes.

Micro Hydropower (MHP) is one of the earliest smallscale renewable energy technologies, and is still an important source of energy today. Micro-hydropower systems are relatively small power sources that are appropriate in most cases for individual users or groups of users who are independent of the electricity supply grid. Micro hydro power systems does not require advanced techniques to facilitate and operate, which means that the installation and operation can be done by local communities [3]. Hydropower systems are classified as large, medium, small, mini and micro according to their installed power generation capacity. Hydropower has various degrees of 'smallness'. There is still no internationally agreed definition of 'small' hydro [4-6], the definition varies from country to country [7]. 
A common classification of hydro power plants based on capacity is presented as follows: A micro-hydropower system is generally classified as having a generating capacity of less than $100 \mathrm{~kW}$. Systems with a generation capacity of between $100 \mathrm{~kW}$ and $1000 \mathrm{~kW}$ are grouped in mini-hydro. Small hydro is defined as having a capacity of more than $1.0 \mathrm{MW}$ and up to $10 \mathrm{MW}$. Systems with a generation capacity of greater than $10 \mathrm{MW}$ and less than $100 \mathrm{MW}$ are classified as medium. Above $100 \mathrm{MW}$ the system is referred to as large hydro power plant $[8,9]$.

Recently, the Ethiopian government in collaboration with other stake holders has been engaged to build many hydropower generations at different scales. Different universities in the country and nongovernmental organizations are also engaged in the study of potential of rivers for micro hydro power generation. The power generation potential of rivers in north shoa zone of the Amhara regional state is studied [10]. According to this assessment the rivers have the potential to generate up to $52.19 \mathrm{kw}$.

However in its present conditions, it is not only economical, but also impossible to address the power supply to the rural areas. Thus, off grid renewable energy or climate proof system types are preferable. In view of above stated problems this study has been designed to assess the technical, and socio economic status of water mill sites for micro hydro power development.

\section{Methodology}

The methodology used for the technical as well as the socio economic assessment includes the collection of primary and secondary data through:

1) Interview Questionnaires, and;

2) Direct observation and measurement.

a. Interview.

For the socio economic assessment, a structured interview questionnaire were designed to access qualitative, multiaspect information of the water mills, rivers and the villages [11]. The numbers of households were selected randomly based on the population size of the area. Mill owners, staffs from Kebele, and other institutions were interviewed to collect general data about the village and the water mill.

b. Head Measurement.

The gross head in this study is the altitude difference between the inlet and outlet of the water mill. In addition to measuring the gross head of the existing water mill we measure the maximum head that can be generated using the run of river around that area. The head measurement is carried out through on site measurements with the help of GPS.

c. Flow rate measurement.

The measurements of river flow rate were done by floating method. Although not as accurate as a measuring device such as a flume or a flow probe, the float method can provide an educated estimate. This method involves measuring the surface velocity of the water with a floating object, and then multiplying this velocity by the width and average depth of the channel $[12,13]$.

$$
\mathrm{Q}=\mathrm{A} \times \mathrm{V}
$$

Where the area $\mathrm{A}$ and velocity $\mathrm{V}$ are calculated as:

$$
\begin{gathered}
A=W \times D \\
V=s / t
\end{gathered}
$$

$\mathrm{Q}=$ flow rate, $\mathrm{W}=\mathrm{Width}$ of Channel, $\mathrm{D}=$ Depth of Water, $\mathrm{s}=$ distance traveled, and $\mathrm{t}=$ time.

To measure the flow rate using the float method:

a) Choose a suitable channel section with minimum instability.

b) Mark the beginning and end of the distance the floating object will travel.

c) Throw the floating object at the beginning of the stream.

d) Using a stopwatch, measure the time the float takes to travel down the length of stream.

e) Repeat step (d) at least three times and determine the average time taken for the float to travel the stream.

f) Measure stream's width and depth across the downstream marker section using a meter stick. Finally, take at least five depth measurements at regular width intervals.

\section{Study Area}

The present study was done in areas covering North Shoa zone of Amhara region, Ethiopia, one of the promising Zones for development of micro hydro in the Amhara Region, according to a previous study [4]. The Zone is bordered on the south and the west by the Oromia Region, on the north by Debub Wollo, on the northeast by the Oromia Zone, and on the east by the Afar Region. The studies were conducted on 14 selected water mill sites, on seven rivers.

\section{Results and Discussion}

i. Technical aspect assessment and analysis.

The objective of the technical assessment is to investigate the water mill site power generation potential for microhydro power generation. One of the most important activities in potential site identification is to measure the water discharge and the head that could be utilized for microhydropower generation.

The head and flow rate measurements and calculations are done as described in the methodology section. The hydropower generation potential of the sites was computed using $[3,10,14]$ :

$$
P=\rho g Q H
$$

Where:

$\mathrm{P}=$ Power $($ Watt $)$.

$\rho=$ Density of water $\left(\mathrm{kg} / \mathrm{m}^{3}\right)$.

$\mathrm{Q}=$ flow rate $\left(\mathrm{m}^{3} / \mathrm{s}\right)$. 
$\mathrm{g}=$ the gravitational constant $\left(\mathrm{m} / \mathrm{s}^{2}\right)$.

$\mathrm{H}=$ Head measured $(m)$.

Table 1 shows the measured head, calculated flow rate, the hydraulic power generation of the sites, and the status of the mills.

Table 1. Technical Assessment and Analysis.

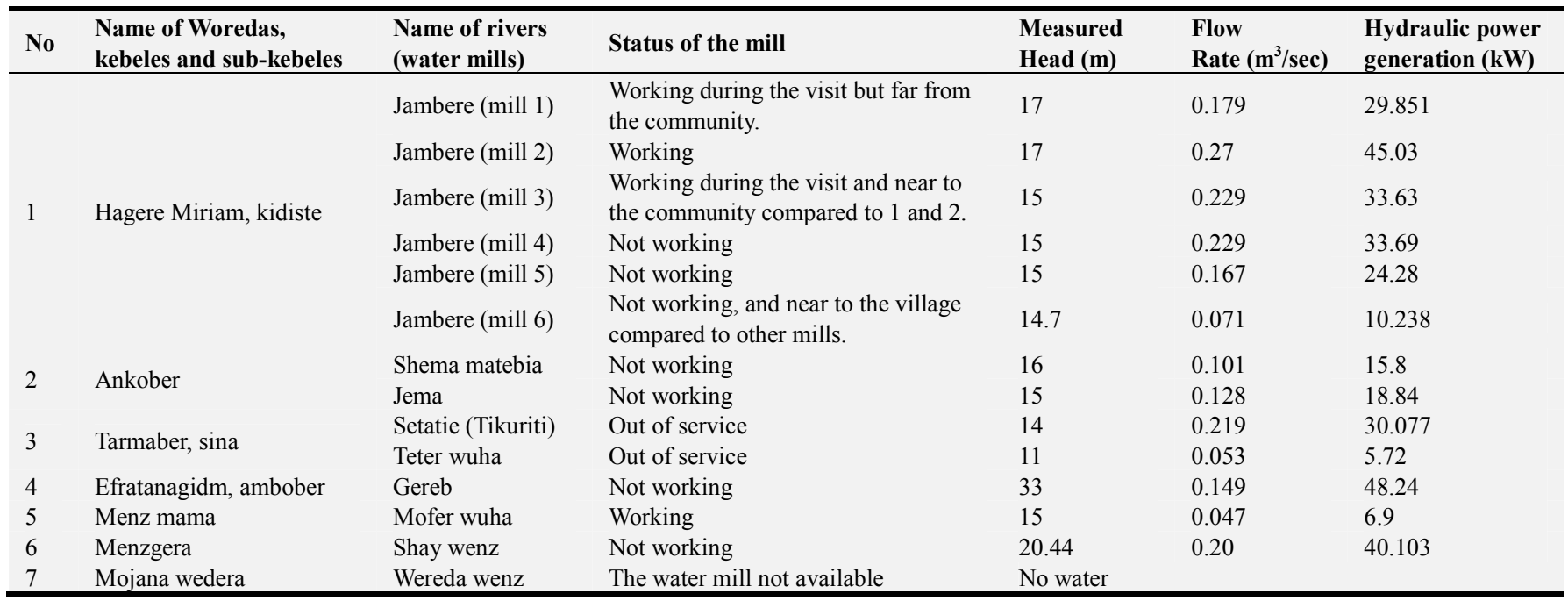

He calculated power generation potential is the theoretical optimum limits of hydroelectricity production of the mill site which represents the maximum power that can be generated during the dry season [15]. The estimated minimum power generation potential is $5.72 \mathrm{kw}$ from Teter wuha mill site, and the maximum is $48.24 \mathrm{kw}$ from Gereb mill site. The average flow rates obtained here can be taken as the minimum values since the assessments were conducted during the dry season.

ii. Socio economic assessment.

After interviewing households, mill owners, and officials of the kebele, and analyzing the information collected the following table were prepared.

Table 2. Socio - economic assessment.

\begin{tabular}{|c|c|c|c|c|c|c|}
\hline No & Woreda & Kebele & Name /water mill & $\begin{array}{l}\text { No. of house } \\
\text { holds }\end{array}$ & $\begin{array}{l}\text { Side Effect on the } \\
\text { village community }\end{array}$ & Social institutions \\
\hline 1 & $\begin{array}{l}\text { Hagere Mariam, } \\
\text { kidiste }\end{array}$ & Kidiste & Jambere (mill 1-mill 6) & 55 & No effect & $\begin{array}{l}\text { Kebele, agricultural and police } \\
\text { office, health center, and a church. }\end{array}$ \\
\hline \multirow{2}{*}{2} & \multirow{2}{*}{ Ankober } & Layegorbela & Shema matebia & 200 & No effect & Church and satellite school (1-4). \\
\hline & & Mehale wenz & Jema & 67 & No effect & - \\
\hline \multirow{2}{*}{3} & \multirow{2}{*}{ Tarmaber } & Sina & Setatie (Tikuriti) & 60 & No effect & - \\
\hline & & Sina & Teter wuha & 35 & No effect & - \\
\hline 4 & Efratanagidm, & Ambober & Gereb & 85 & No effect & - \\
\hline 5 & Menz mama & 08 kebele & Moferwuha river & 120 & No effect & School (1-4) \\
\hline 6 & Menzgera & $\begin{array}{l}\text { Tsehayisina08 } \\
\text { Kebele }\end{array}$ & Shayi wenz & 128 & No effect & \\
\hline 7 & Mojana wedera & Wedera & Wedera wenz & & & \\
\hline
\end{tabular}

Table 2. Contiuned.

\begin{tabular}{|c|c|c|c|c|c|}
\hline No & $\begin{array}{l}\text { Willingness of the community and } \\
\text { concerned local administration person. }\end{array}$ & $\begin{array}{l}\text { The village community } \\
\text { energy source for lighting }\end{array}$ & $\begin{array}{l}\text { Distance to the } \\
\text { national grid }\end{array}$ & $\begin{array}{l}\text { Population } \\
\text { distribution }\end{array}$ & $\begin{array}{l}\text { Willingness of the mill } \\
\text { owner to cooperate? }\end{array}$ \\
\hline 1 & They are voluntary & Solar, Kerosene & Very far from the grid & $\begin{array}{l}\text { Partially } \\
\text { dense }\end{array}$ & Yes \\
\hline \multirow[b]{2}{*}{2} & They are voluntary & Kerosene, solar, wood & Around $2.5 \mathrm{~km}$ & Scattered & yes \\
\hline & They are voluntary & Kerosene, solar, wood & Around $10 \mathrm{~km}$ & $\begin{array}{l}\text { Partially } \\
\text { dense }\end{array}$ & yes \\
\hline \multirow[b]{2}{*}{3} & They are voluntary & Kerosene, solar, wood & Around $5 \mathrm{~km}$ & Dense & yes \\
\hline & They are voluntary & Kerosene, solar, wood & Around $5 \mathrm{~km}$ & $\begin{array}{l}\text { Partially } \\
\text { dense }\end{array}$ & yes \\
\hline 4 & They are voluntary & Kerosene, solar, wood & Very far from the grid & $\begin{array}{l}\text { Partially } \\
\text { dense }\end{array}$ & Yes \\
\hline 5 & They are voluntary & Kerosene, solar, wood & --- & ---- & Yes \\
\hline 6 & They are voluntary & Kerosene, solar, wood & ---- & ---- & Yes \\
\hline 7 & \multicolumn{5}{|c|}{ Above 100 households but no water flow through the river } \\
\hline
\end{tabular}


From the socio economic analysis:

a. There will be no side effect on the community if the project is implemented.

b. All the community members including the mill owners agree voluntarily for upgrading the mill sites to micro hydro power plant.

c. Almost all mill sites (villages) are at least $5 \mathrm{~km}$ far from the main grid except Shema matebia which is $2.5 \mathrm{~km}$

d. In the case of Shema matebia mill site, the estimated power generation potential is $15.5 \mathrm{kw}$, the number of households is 200, and the population density is scatted. Considering this, it will not be feasible to implement MHP for this site.

\section{Conclusion}

Use of micro hydro power plants is a promising way to deliver energy for off grid communities in developing countries. However, an assessment on technical and socio economic aspects are very essential before constructing and implementing it. Conducting the right assessment by participating the stake holders is crucial in identifying practical solutions and solving the energy problems of remote areas.

There are a number of existing and former mill sites in the study area. A technical and socio economic assessment of mill sites in North Shoa zone of the Amhara regional state, Ethiopia has been done for micro hydro power generation. All the sites except teter wuha and wedera wenz, found to be technically, socially, and economically feasible. No water flows through Wedera wenz mill site.

Through this study, out of the 14 mill sites investigated, 12 of them can generate above $5 \mathrm{kw}$ with $80 \%$ efficiency during the dry season, which predicts a tremendous potential to harvest energy using micro hydro power plants and power the communities.

The study also shows that the Existing as well as former mill sites in North Shoa zone, were mostly located in mountainous regions which offers an interesting opportunity for micro hydropower generation for meeting the energy demand of the villages at least $5 \mathrm{~km}$ far from the main grid.

\section{References}

[1] Hydropower status report 2017, international hydropower association, IHA, available at, www.hydropower.org.

[2] Power africa in Ethiopia, 2016, availabel at, www.usaid.gov.

[3] Tamrakar, A., et al. "Hydro Power Opportunity in the Sewage Waste Water." American International Journal of Research in
Science, Technology, Engineering \& Mathematics 10 (2): 179$183,2015$.

[4] Yirgalem Damtew, and Gashaw Getenet, "Assessment of Hydropower Potential of Selected Rivers in North Shoa Zone, Amhara Regional State, Ethiopia." American Journal of Energy Research, vol. 7, no. 1, 15-18, 2019.

[5] Anaza, S., et al. "Micro hydro-electric energy generation-An overview." American Journal of Engineering Research (AJER) 6 (2): 5-12, 2017.

[6] A. Gaglianoa, G. M. Tinab, F. Noceraa, F. Pataniaa "Technical and Economic Perspective for Repowering of Micro Hydro Power Plants: a Case Study of an Early XX Century Power Plant”, Energy Procedia 62, 512 - 521, 2014.

[7] Anup Gurung, Ian Bryceson, Jin Ho Joo and Sang-Eun Oh. ' Socio-economic impacts of a micro-hydropower plant on rural livelihoods". Scientific Research and Essays Vol. 6 (19), pp. 3964-3972, 8 September, 2011.

[8] Masahiko Fujii, Soichiro Tanabe, Makoto Yamada, Taketoshi Mishima, Takahiro Sawadate, Shinji Ohsawa, "Assessment of the potential for developing mini/micro hydropower: A case study in Beppu City, Japan”, Journal of Hydrology: Regional Studies 11, 107-116, ELSEVIER, 2017.

[9] J. A. Otun, J. I. Onemano, A. W. Alayande, "Assessment of The Hydropower Potential of Kangimi Reservoir In Kaduna State Nigeria", Nigerian Journal of Technology (NIJOTECH) Vol. 31, No. 3, pp. 300-307 November, 2012,.

[10] Bhat, V. I. and R. Prakash. "Life cycle analysis of run-of river small hydro power plants in India." The Open Renewable Energy Journal 1 (1), 2008.

[11] Nasir, B. A. "Design of micro-hydro-electric power station." International Journal of Engineering and Advanced Technology 2 (5): 39-47, 2013.

[12] Casini, M. "Harvesting energy from in-pipe hydro systems at urban and building scale." International Journal of Smart Grid and Clean Energy 4: 316-327, 2015.

[13] Kengne Signe, E. B., Hamandjoda, O., Nganhou, J. and Wegang, L. "Technical and Economic Feasibility Studies of a Micro Hydropower Plant in Cameroon for a Sustainable Development"'. Journal of power and energy engineering, 5, 64-73, 2017.

[14] Olumuyiwa Oludare, "Studies on Small Hydro-Power Potentials of Itapaji Dam in Ekiti State, Nigeria", International Journal of Engineering Science Invention, Volume 5 Issue 1, PP. 28-36, 2016.

[15] Emmanuel I. Igweonu and Robert Ben Joshua, "Small Hydropower (SHP) Development in Nigeria: Issues, Challenges and Prospects", Global Journal of Pure and Applied Sciences VOL. 18, NO. 1\&2, 2012: 53-58, 2011. 